\title{
Evaluating the Impact of Betrayal for Children Exposed in Photographs
}

Eileen L. Zurbriggen*, Gale E. Pearce and Jennifer J. Freyd University of Oregon

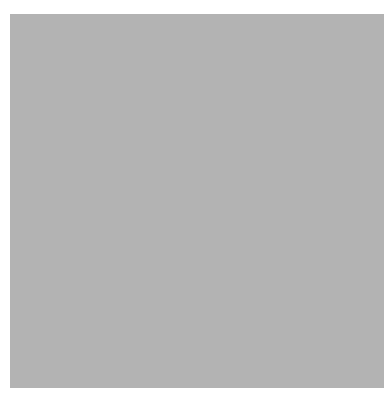

*Correspondence to: Eileen L. Zurbriggen, Department of Psychology, Room 277, Social Sciences 2, University of California, Santa Cruz, Santa Cruz, CA 95064, U.S.A. E-mail: zurbrigg@ucsc.edu
Elements of betrayal trauma theory (Freyd, 1996) are used to evaluate potential negative and positive consequences for children who serve as artistic models, particularly those who model for their artist parents. Several dimensions are considered in evaluating the likelihood of harm: nudity, motives of the artist, consent, external vulnerability, and objectification. Recommendations to artists include appointing an advocate for the child, discussing photographic sessions and allowing observers, and going beyond standard release procedures. Similarities to the domains of creative writing and research psychology are considered. Copyright (C) 2002 John Wiley E Sons, Ltd.

$\mathrm{A}$ rtists and photographers frequently choose children as the subject of their art. This is understandable given the many qualities of children that make them beautiful: their sincerity, spontaneity, and unselfconsciousness, as well as their inherent vulnerability. Because of this vulnerability, however, there is a real possibility of exploitation when children are used to further the professional or artistic goals of adults. In this article, we explore the conditions under which serving as photographic models may be harmful to children. We begin with the assumption that artists are concerned about the well-being of the people they depict in their art, and that this is especially the case when parents use their own children as models. We describe a number of dimensions that relate to the possibility of harm. We also offer some recommendations geared especially towards parents who use their children as models. We hope that this article leads to further thought and discussion of these issues and therefore to a balance between the important goals of protecting children's interests and rights and providing artists (and, indeed, all of us) with the opportunity for full and free creative expression.

\section{Two separate actions}

There are two separate aspects of the artistic process to consider when evaluating the potential for harm for a photographic model. First, there is the experience of actually modelling for the photos. The actions of the child and the 
interactions with other people could have positive or negative effects, irrespective of whether anything is being committed to film. In addition, there may be effects that are unique to the experience of being the subject of an artist's gaze, of being a model, or of being photographed.

The second action that takes place is that the photographs are published, exhibited or disseminated in some other way. Although most discussion of this topic has focused on the first action, both actions have the potential for harming the child; attention should therefore be paid to both.

\section{Childhood sexual abuse and betrayal trauma theory}

Although our focus will not be on those photographs that clearly depict sexual abuse, we would like to begin our discussion there. There is good evidence that the experience of being sexually victimized is likely to have serious negative consequences for children, both immediately and in later life (for reviews, see Browne and Finkelhor, 1986; Dhaliwal and others, 1996; Putnam and Trickett, 1993). Photography of children in explicitly sexual contexts almost by definition requires sexual abuse at the time the picture is taken. In addition to the harmful effects that are likely to result from the actions being photographed, the dissemination of the photographs may have additional negative consequences. Their publication or exhibition is a further betrayal of the child's trust, a further violation of his or her privacy, and may lead to a feeling of greater traumatization. ${ }^{1}$

Betrayal trauma theory. Betrayal trauma theory (Freyd, 1994, 1996, 1997, 1999, 2002) was developed to explain why people are more likely to have impaired memory for some traumatic experiences (for example, childhood sexual abuse) than for others (for example, natural disasters such as hurricanes). This theory provides a useful framework with which to consider the potential impact of photographing children. The core tenet of the theory is that impaired awareness of trauma will be more likely to occur when the trauma involves a social betrayal and the consequences of acknowledging that betrayal are great. For example, consider the case of a child who is being physically or sexually victimized by a caretaker - someone the child depends on to meet all of her emotional and physical needs. If this child remains fully aware of all the terrible things being done to her, she is likely to become angry with the abuser and to withdraw physically and emotionally. In so doing, she would weaken the attachment bond with her caretaker, and therefore make it less likely that her needs will be met. In essence, she would be jeopardizing her survival. The more adaptive choice might be to remain consciously unaware of the abuse, to minimize or deny it, to forget it, or to dissociate herself from it; this choice would allow the vitally important attachment bond to be preserved. ${ }^{2}$

\footnotetext{
${ }^{1}$ It is possible that there may also be some positive results from the dissemination of the photographs. For example, dissemination may lead to the discovery of the abuse and the arrest and conviction of the abuser. Photographs may also help the survivor to remember or understand the abuse or to validate their experience.

${ }^{2}$ See Freyd (1996), pp. 9-11 and 60-78 for a fuller description of betrayal trauma theory. Summit's sexual abuse accommodation syndrome (CSAAS; Summit, 1983) and Goddard and Stanley's (1994) application of hostage theory to childhood sexual abuse are also relevant. Summit's CSAAS shares with betrayal trauma theory the emphasis on the preservation of an important relationship; however, it focuses on both conscious and unconscious information distortion (the focus of betrayal trauma theory is on unconscious information distortion). Goddard and Stanley's application of hostage theory also places an emphasis on the relationship between victim and perpetrator and on the potential adaptiveness to the victim of creating, preserving, or strengthening that relationship. They discuss a broad range of defence mechanisms that can aid in achieving the goal of preserving the relationship; some of these defence mechanisms (for example, dissociation and denial) are types of information distortion.
} 
This 'knowledge isolation' (Freyd, 1996, p. 26) can range from minor memory distortions to pervasive amnesia or denial. For example, of ten children involved in Swedish pornography (Svedin and Back, 1996) not one volunteered information about the abuse. When police uncovered the photographs and videos and interviewed the children, most of them had difficulty remembering the events captured on film. For some of these children, the sight of the photographic evidence served as a reminder of the events, which they were then able to discuss. For other children, however, this was not the case. Svedin and Back report that one girl 'feels very ill at ease when she sees the pictures and says that she has now, of course, seen the evidence, even though she cannot remember the events ... . When [another child] is presented a photograph showing his face he denies that it is him.' (Svedin and Back, 1996, pp. 43-44).

Other traumatic events that include a component of betrayal are also more likely to lead to some degree of unawareness while the mistreatment is occurring or some amount of forgetting afterwards. For example, the relationship between soldiers and the unit commanders they serve under is in some ways similar to the relationship between children and parents-both children and soldiers are relatively powerless and their survival depends, to a large extent, on the actions of the other (Shay, 1994). Therefore, certain combat situations may be likely to result in reduced awareness. In one high-profile example, Hugh Thompson (the one US soldier who tried to stop the My Lai massacre) did not remember the incident when questioned by US Army investigators two years later. His memory came back slowly (over the course of several days) and only after he was reminded of specific incidents such as hitting a tree with his helicopter (Mason, 1997, cited in Freyd, 2002, pp. 154-155). Unawareness (or 'betrayal blindness') can also occur in situations that are more commonplace. For example, an infidelity is often obvious to outside parties, but the spouse seems blind to the evidence that a betrayal is occurring.

In addition to the presence of social betrayal, there are six other factors that betrayal trauma theory predicts will be associated with unawareness of mistreatment (Freyd, 1996, p. 140): (a) explicit threats demanding silence; (b) alternative realities in the environment (for example, the abuse context is different from the non-abuse context); (c) isolation during the abuse; (d) young age at onset of abuse; (e) alternative reality-defining statements by caregiver (for example, 'He didn't hit you hard. You just bruise easily.'); and (f) lack of discussion of the abuse.

It is important to state clearly that coercive sexual activities, whether or not they are photographed, are harmful to the physical and mental health of the children involved. These activities should be illegal, and we should make every effort to ensure that any violations are quickly detected and stopped. Our focus in this article, however, is on photographs whose content is ambiguous and whose potential for harm is not clear; for example, photographs that involve nudity without overt sexuality, or that are perceived as sexual by some viewers, but not by the artist or the model. We also want to open a dialogue of a more general nature, that could be applicable to any kind of photographs of children (for example, in advertising); this dialogue includes attention to issues of consent. We want to discuss the special case of the artist photographing his or her own children. Finally, as mentioned above, we will consider both the action of taking the photograph and the action of disseminating it. 


\section{Effects of photographing children}

Much discussion about photographing children has revolved around legal, philosophical, or political arguments about child pornography (Greenhouse, 2002; Peterson, 2002). There has been relatively little conversation about instances in which seemingly innocuous modelling might pose an unintended risk to the child's rights. In addition, very little empirical evidence has been presented. Carefully designed studies can help us determine how acting as photographic models impacts children, and what aspects of the modelling process might put them at risk for psychological harm.

Unfortunately, studies that look specifically at the experience of engaging in photographic modelling have not, to our knowledge, been conducted. However, it is possible to draw inferences about the potential for harm in this situation by considering what we know generally about child development and attachment. In addition, we can use betrayal trauma theory (and other theories about childhood sexual abuse) as well as other theories about objectification (for example, Fredrickson and Roberts, 1997) to inform our analysis.

\section{Positive effects}

Although our purpose in this article is to encourage discussion of the possible negative effects of serving as a photographic model, we realize that there are a host of positive outcomes that might also occur, and that these effects might be especially strong when the artist is also the parent. We mention a few of these potential effects below; however, this is not meant to be an exhaustive list.

During the photographic session, the parent/artist and child/model spend a quantity of time in each other's company. There is the opportunity for the two to develop a closer bond. The child may feel proud and happy to be such an important part of the parent's work. He or she is likely to learn about art and the artistic process and may in fact be an active agent in the creation of the artistic images. This appears to have been the case for the children of Sally Mann, who describes the artistic process of photographing her children as follows:

It's not like these kids had to keep some shred of personal dignity squirreled away from their prying Mom's camera lens. They were-and are still-active participants in the art-making that goes on all around them .... . [A]ny parent knows that you can't force a child to make art; they have to cooperate, they have to want to be part of the process. When we made these pictures, the kids knew exactly what to do to make an image work: how to look, how to project degrees of intensity or defiance or plaintive, woebegone, Dorthea-Lange dejection. I didn't pry these pictures from them-they gave them to me (Mann, 1998).

Other possible positive outcomes for the child include pride at making art and of accomplishing the sometimes difficult work of posing; posing may also be a way for a child to build discipline. Finally, the session may be fun for artist and model alike. Both may experience the session as an exciting and engaging form of play.

The dissemination of the picture might also result in positive consequences. The child may earn the esteem of their peer group because of their celebrity status, and their self-esteem 
may be enhanced from the experience of having their image admired. Certain career opportunities (for example, acting) might be facilitated by media exposure. Less directly, the exhibition or publication of the photographs advances the parent's career, and provides income that the artist uses to support his or her family.

\section{Negative effects}

Although positive effects no doubt exist, and may, in fact, be more common than negative effects, our main purpose in this article is to think about the potential for harm to children when they are used as photographic models. There are a number of dimensions that may be important in evaluating the likelihood of harm. We focus on a few items from what could be a much longer list.

Nudity. One of the important factors government prosecutors use in making a judgment about whether photographic representations of children are pornographic is whether the children are nude. Certainly, nudity is almost always present in child pornography. However, it does not necessarily follow that all nude images of children are pornographic, or even that all nude images are representations of sexuality. In fact, there does not appear to be any evidence that nudity per se is harmful to children (Story, 1979). However, this does not necessarily mean that the experience of being photographed nude, or of having those photographs distributed, will have no negative consequences. Especially in a culture in which nudity is both sexualized and seen as shameful, feelings of guilt or shame could arise, either during the photographic session or later. In addition, if the child interacts with peers and others who do not share the family's attitudes about nudity, these relationships could suffer.

Motives of the artist. One useful framework for thinking about a parent's goals in childrearing was proposed by Dix (1992). He divides parental goals and concerns into three categories: self goals, empathic goals, and socialization goals. Self-oriented goals are concerned with making the parent's life happier, more pleasant, or more satisfying. One example of a self goal would be a parent's desire for pleasant conversation with other adults. Empathic and socialization goals, on the other hand, are child-orientedconcerned with the health, safety, happiness, and development of the child. In empathic goals, the focus is on the child's feelings and on meeting the child's stated wishes; for example, finding toys or games that make the child happy. In socialization goals, the focus is on what will benefit the child, but will not necessarily please them. For example, children may prefer to eat only cookies and ice cream, but their health and physical development will suffer if they are allowed to do this on a regular basis.

All three types of goals are legitimate and necessary for effective parenting. In addition, multiple goals can often be satisfied at once. For example, a bedtime story ritual may simultaneously fulfil numerous goals. The parent is meeting the self goals of protecting his or her evening free time, minimizing conflict with the child (and the negative emotions that would result), and enjoying pleasurable and intimate contact with him or her. The child is also experiencing pleasure from the warm physical contact, the intellectual stimulation of the story, the comfort of the routine, and from the relatively undivided attention of the parent. Socialization goals are also being met, as the child's cognitive development and reading ability will benefit from this activity. 
At other times, however, goals will work at cross purposes. For the parent whose toddler is clamouring for attention, the self goal of conversing with another adult is clearly in conflict with the empathic goal of making the child happy. The socialization goal of vaccinating one's child in order to prevent future bouts of serious diseases conflicts with the empathic goal of minimizing his or her fear and pain in the present moment.

It is useful to think about Dix's classification of goals when considering an artist's motives for photographing a child. It may be that this is one of the happy moments when many different goals can be satisfied at once. The artist may be meeting a number of creative and financial self goals. If the child enjoys the photographic session, then empathic goals are being met. It is also possible that some socialization goals (for example, helping the child to develop as an artist) are being pursued.

On the other hand, there may be a conflict between goals. One concern is that self goals are primary in the sense that without them the photographic session would be unlikely to take place. Even if child-centred goals are also present, self goals are likely to be the most salient to the artist during the shoot. Given the primary status of these goals, certain psychological consequences are likely. Two that are mentioned by Dix (1992) include a shift in attentional focus and a difference in how the same event might be interpreted. Attention is focused less on the child's subjective reactions to the session, and more on features of the situation relevant to the self goals, for example, the lighting or the physical and aesthetic appearance of the child. In addition, the artist's primary goal orientation may affect how he or she interprets an event. A child's silence or lack of movement may be interpreted not as fatigue (as might be the case if empathic goals were foremost in mind) but as compliance with the requirements of being a model.

Note that it might be possible to make some inferences about an artist's motives, based on their photographs, but these inferences may well be inaccurate. Thus, this is an aspect that does not lend itself well to legal regulation. That does not imply, however, that it is an aspect that parents and artists should ignore. On the contrary, because it is likely to remain outside the purview of the legal system, it should perhaps receive an even more careful consideration from the perspective of moral and ethical beliefs and values. Because there may be a conflict between an artist's self goals and the empathic and socialization goals that focus on the child's needs, it is essential that the artist be cognizant of this conflict of interest, so that the potential for harm to the child can be minimized.

Consent. Consent is obviously a very important concept in considering the possibility of harm. A child model should be a willing participant throughout the artistic endeavour. There should be no coercion of any kind - subtle or overt, physical, mental, or emotional. The child should also be able to revoke consent at any time. Simply put, if the child is unhappy, if they want to stop the photo session, the artist should stop.

While important, this recommendation does not provide enough protection. A fundamental question concerning consent is whether a child has developed cognitively and emotionally to the point where consent is possible or meaningful. Very young children do not understand what a camera is or what it means to have one's picture taken. Older children do understand the photographic process, but they may not understand all the implications of posing in certain settings or in certain ways. In addition, some questions relevant to consent may only be fully comprehended by adults. For example, we 
might want to ask: 'Is it all right with you if I make my career off your image?' It may not be possible for a child or a young adolescent to understand such a question. A child's consent, then, is not a guarantee that there is no potential for harm.

On the other hand, there may be some circumstances in which a child's lack of consent can be overridden. Certainly, there are times when children are required to participate in activities in spite of their refusal to consent. They must follow rules about what they can eat, when and how they should bathe, when they go to sleep and wake up, and about how many television shows they can watch. They are vaccinated without consent (and sometimes over very vocal protestations), they are required to attend school, and sometimes parents insist that their (non-consenting) children be part of a formal or informal family portrait. Are there any differences between these situations and the situation of a parent/artist who uses a child model without his or her consent?

Dix's classification of parental goals provides a partial answer to this question. It is most justifiable to ignore a child's lack of consent when socialization goals are being pursued, and less justifiable when the goals are self-oriented. Of course, it can sometimes be difficult to distinguish between the two. When a father forbids his son to study ballet and instead forces him to play football, is he pursuing a socialization goal or the self goals of avoiding embarrassment with his friends and feeling adequate in his masculinity? One of the tasks of enlightened parenting is to strive for better understanding of which type of goal is truly primary.

Issues of consent are to some extent moot when empathic goals are being pursued. That is, if one's goal is to find activities that the child will enjoy, the decision of whether to override the child's lack of consent will not need to be made, because children will presumably freely consent to participate in activities that they enjoy. However, it is important to remember that the fact that a child enjoys an activity and freely consents to it is no guarantee that the activity is beneficial or even benign. If given the choice, children might eat mostly dessert and no vegetables, with resulting negative effects on their health and physical development. Similarly, children may want to participate in activities that are dangerous or harmful such as playing with matches. Thus, while it is important to obtain children's consent, and important to overrule their lack of consent only when this can be clearly justified, the presence of consent does not by itself guarantee that there is no possibility of harm.

We do not believe that there is one correct set of answers to questions about consent. In fact, our thinking about children's abilities and rights to determine their own fate and order their own environment is very much a cultural and historical construction. The general direction of historical change, however, has been towards acceptance of greater autonomy for children. The burgeoning 'children's rights' movement (Hart, 1991; Pardeck, 2002) can be classified as a civil rights movement, similar to previous movements advocating for the rights of women, indigenous peoples, minority ethnic populations, and lesbians and gay men. One outcome of this movement is an increased focus on consent. We are encouraged to think much more deeply and seriously about when and why we sidestep the issue of consent for children.

External vulnerability. Even if children freely consent to be photographed, and to have the photographs disseminated, they may still be vulnerable to harm. Over and above an 
individual's concerns about privacy and potential embarrassment, there are real world risks associated with physical and psychological exposure. In other words, irrespective of one's own feelings about a photograph, other people may take advantage of exposed vulnerabilities.

We alluded to this concern in our discussion of nudity. Publication of nude photographs may have real social consequences, especially if one lives in a community that considers nudity sinful or deviant. There are potentially many other negative consequences for exposing one's vulnerabilities publicly. Some of these consequences might appear immediately, but others might not become apparent until years later. For example, if a seven-year-old child is depicted as having just wet her bed, she may be teased or taunted by other seven-year-olds. If, on the other hand, there is a subtly erotic component to the photograph, this might not provoke a reaction from her schoolmates because they do not yet perceive the erotic content. Once these children become adolescents, however, the erotic symbolism of the photograph will be apparent to them, and an entirely different type of harassment might result.

Negative reactions from adults are also possible, and in fact are inherently more dangerous because of the greater power wielded by adults. As an example, consider the potential damage to a girl who has been depicted as if she were a fully grown woman. The potential for harm derives not so much from the high heels and makeup per se, but from an evocation in adult viewers/consumers of a set of beliefs about the child's motives and intentions (for example, that an intent to seduce is present, as it might be in a similarly attired woman). If adults then act on these beliefs by interacting with the child as they would with a seductive adult, this places the child in a vulnerable position because she simply does not have the resources to handle social interactions of this kind.

Objectification. One type of external vulnerability seems important enough to warrant additional discussion. Children exposed in photographs may be vulnerable to being objectified by both the artist and by those who view or purchase the photographs, and there may be harmful consequences that result from this objectification.

One area of psychological research that highlights this potential for harm is the objectification theory of Fredrickson and Roberts (1997). Their theory states that the repeated experience of being objectified, of being treated as an object to be looked at and evaluated, has specific negative consequences for women that include increased shame and anxiety, a lack of connection to one's body, an inability to be aware of and responsive to internal cues or bodily states, and a reduced frequency of being in what Csikszentmihalyi (1990) calls a state of 'flow' — a state of intense and pleasurable absorption in an activity. Although this theory refers specifically to sexual objectification, many of the same outcomes may result from a de-sexualized 'aesthetic' objectification that seems likely to be present (to some extent) in most photography sessions. ${ }^{3}$

Note that a child can be objectified in other ways, and other situations can be eroticized as well. For example, when parents enter their preadolescent daughter in a beauty pageant, they are exposing her to both objectification and sexualization. In other words, these

${ }^{3}$ Of course, children being photographed may be sexually as well as 'aesthetically' objectified. 
danger areas are not unique to a photographic session. They may, however, be greater in such sessions. For example, the experience of being the object of the artist's gaze may be different than the (more generic) experience of simply being observed or viewed. In addition, when the parent is the artist there is an inherent conflict of interest. Both a literal object (the camera) and a different identity and set of needs (those of the artist) come between the child and the parent.

\section{Recommendations - taking the picture}

In the next sections we offer some recommendations that artists may want to consider, especially when using their own children as models. These recommendations were developed in part from a consideration of the seven factors that are predicted by betrayal trauma theory to lead to increased unawareness of mistreatment (as listed above and elaborated in Freyd, 1996, Ch. 6).

\section{Appoint an advocate for the child}

If you are both parent and artist, the possibility of a conflict of interest exists. Consider asking another person to act as an observer, and as the child's advocate. This person may notice signs of harm before you do, or when you are unable to. Even something as simple (and innocuous) as failing to notice the child's fatigue because you are too excited by the perfect light can be prevented if an advocate is present.

An example of a situation where an independent observer might have noticed something that escaped the photographer is described by Sally Mann in her book At Twelve (a collection of photos of 12-year-old girls who are not related to Mann). Writing about a photo of a girl and an adult man, she says:

This child was distinctly reluctant to stand closer to her mother's boyfriend. This seemed strange to me, as it was their peculiar familiarity that had provoked this photograph in the first place. Looking through the ground glass I fretted over cropping her elbow but she would not budge toward him. Several months later her mother shot him in the face with a .22. She testified that while she worked nights at a local truckstop he was 'at home partying and harassing my daughter'. I look at this photograph now with a jaggy chill of realization (Mann, 1988, p. 50).

The dynamic between child and mother's boyfriend was subtle and probably easy to miss. Mann is not trained to interpret or detect unhealthy family dynamics. Still, even an untrained observer who was not also thinking about artistic composition, about the shot she wanted to get, would be more likely to suspect that something was not just 'strange' but seriously wrong. Now imagine that the artist was also the mother. She would likely have many defences operating that would not allow her to see any unhealthy dynamic between her boyfriend and daughter.

This is not to say that much, or even any, harm resulted in this particular case. However, it does illustrate the difficulty of being both a photographer and an advocate for your models at the same time. There is simply less attention available to devote to thinking 
about the child's welfare, because one must also think about composition, lighting, and the mechanics of the photographic process. ${ }^{4}$

It is important to choose the advocate carefully. This person needs to be someone who is able, both in terms of their temperament and their relationship to the artist, to contradict or criticize the artist. Thus, it should not be someone over whom the artist has power-for example, an assistant. If the family has one or more regular child care providers, it might be tempting to entrust this person with the responsibility of being the advocate; however, because there is an employer/employee relationship between the artist and this person, they may not be able to be as protective of the child as is desirable.

One should also think about the philosophical or ethical values that the advocate holds. If we are serious about protecting our children, we would probably choose an advocate who is more conservative than we are, more of an ethical 'stickler'.

The advocate would not necessarily have to be present at all photographic sessions (although that might be best). Instead (or in addition), one could discuss planned photographs with the advocate, who would be charged with thinking of any possible harm that might result.

\section{Talk about the photographic sessions with the child}

Betrayal trauma theory predicts that explicit threats demanding silence and a lack of discussion of abuse are both likely to lead to greater traumatization, unawareness of mistreatment, and forgetting. Obviously, any kind of threats are in and of themselves abusive. But even a more benign lack of discussion of the artistic enterprise is potentially dangerous. The best way to mitigate this danger is to encourage the child to talk about the photographic sessions with others, both within and outside the family. Give the child the opportunity to tell you if something feels amiss to them. Do this both during and after the photo shoot. You may be better able to pick up on subtle indications that something is uncomfortable if you are talking about it at a later time, when your attention can be focused solely on the child, rather than being split between him or her and your work.

\section{Be the same person while photographing as you are in other situations}

Betrayal trauma theory predicts that alternative realities in the environment (abuse context different from non-abuse context) and alternative reality-defining statements by the caregiver are both related to less awareness of mistreatment. The recommendation that we draw from that prediction is to avoid (as much as possible) becoming a different person during the photographic session. It is not that taking on a vastly different persona would have a direct negative effect on the child (although it might, for example if you were cold or harsh). But, if the photographic session seems like a different world, and if you as photographer are a completely different person than you as parent, then it will be harder for the child to communicate to you as parent if anything is not right about time spent with you as photographer.

\footnotetext{
${ }^{4}$ Note that in addition to the potential 'blindness' of the artist to harmful consequences, betrayal trauma theory reminds us that there is a danger that the child will also be 'blind'. He or she is motivated to not notice that a parent is causing them harm, to minimize any harm they do notice, and to deny the harm if someone else points it out to them.
} 


\section{Give your child plenty of attention outside of the modelling situations}

Most children crave attention from their parents and want to please them. If your child only gets your time and attention when serving as a model for your artistic endeavours, then it is going to be difficult for them to speak up about being uncomfortable about modelling (if that is the case), because they would risk losing the benefit of your attention.

\section{Let others observe or participate in the photographic sessions}

Isolation during abuse is another factor related to amnesia for trauma. By having an advocate present, complete isolation is avoided. There are additional ways to open up the process, however. For example, photo shoots in public rather than private spaces are less isolated. If studio work is necessary or desired, there are still ways to make the experience less isolating - for example, by allowing friends of the child to be present, if he or she desires.

\section{Recommendations-disseminating the picture}

\section{Go beyond the standard blanket release procedure}

While it may be fair to ask adults to sign away all rights to their own image, in perpetuity, it is not fair to ask a child to do so. A child should be able to request that a photo of them not be shown or not be used, even if it has been exhibited before. When they turn 18 the artist may then ask them to sign away all rights, but not before. We consider this the minimal form of protection regarding dissemination that should be afforded to child models.

A stronger recommendation would be to extend that sort of protection (no blanket releases) even after the child models have reached the age of majority. Jock Sturges is one photographer who follows this model. Sturges has photographed families at nude beaches in southern France for many years. He does not follow the standard model release procedures for any of the subjects of his photos, child or adult. Here is his explanation of why he dislikes such releases.

\footnotetext{
Most photographers have their subjects (or parents or guardians) sign a model release at the time the photographs are taken, which protects the photographer from legal repercussions. Once a release has been signed, the pictures are out of the subject's control. I do not use releases. When I want to use a photograph, I contact each person, explain the context in which I wish to exhibit or publish the picture, and get permission for that specific purpose. Either I stay in touch with people or I don't deserve to use their pictures. People mature, grow older, change. I never want to be guilty of making assumptions about those changes (Sturges, 1991, pp. 87-88).
}

An even more radical proposal would be to refrain from publishing or exhibiting any photograph of a child until the child is legally able to consent. Very young children are not able to understand much about the symbolic meanings of the photographs they are in. A pre-pubescent child may completely miss subtle sexual symbolism in a photograph, imagery that would be perceived as sexual by an adult. Is it fair to disseminate such a picture of a child before they have developed to the point of understanding the imagery? 
Young children are unashamed of their bodies and are not easily embarrassed. But they may become much more modest as they develop. A child may consent to the publication of a photograph when they are six, but may regret that decision when they are 14. Is it fair to disseminate the photograph before the child has developed enough to know what it is they are consenting to?

Another photograph from Mann's At Twelve collection is worth considering. In this picture, a girl is positioned in the centre; to her left and right hang four decapitated, skinned deer, suspended from their hind legs, which are spread in V shapes. Severed heads and forelegs litter the ground around her. Mann says,

As I pulled her [the child model's] jacket back, to separate her white-shirted figure from the darkness of the shed, I thought I might have heard a murmur [from the girl's relatives, who were observing]. After a few minutes I relaxed enough to identify the prevalence of the $\mathrm{V}$ shapes in the scene and without thinking I asked Kelly to spread her legs [thus creating a contrasting $\mathrm{V}$ shape]. This time the murmur was audible, but I could see that the picture was complete (Mann, 1988, p. 38).

Although the model did not object to this pose during the session, it is possible that she might later be disturbed by the visual juxtaposition between herself and butchered animals. Does an artist have any responsibility to be concerned about such a possibility? If protecting children's interests is a high priority, then such a responsibility should be, if not embraced, at least considered. Compromise approaches are also possible. For example, if a photograph is published as part of a book (as this one was) it is not possible for the photographer to later remove it from circulation. On the other hand, if a photograph is exhibited rather than published, the artist can later decide not to exhibit it again, and could even destroy the negative (or give it to the model). This latter approach has the advantage of offering some protection to the child while at the same time having less of a negative impact on the artist's career.

We realize that this proposal (even in a modified form) is unlikely to be embraced by the artistic community. Especially in commercial photography, the financial cost of such a proposal would be high-ad campaigns and films featuring children would have to be put in storage for years. Practically speaking, this would mean that child models would no longer be used. Even if this strategy is not widely accepted, however, individual artists might consider adopting it in some form, especially for particularly sensitive photographs. ${ }^{5}$

\section{Discuss dissemination decisions with the child's advocate}

The conflict of interest inherent in being both parent and artist is present when taking the photographs and when making decisions about dissemination. In fact, this conflict may actually be greater during this latter stage, because the photograph has become a physical object that has value (both psychological and financial) to the artist. This introduces an additional conflict of interest-it may be more difficult for a parent to evaluate the

\footnotetext{
${ }^{5}$ The recent Let Kids be Kids campaign (North Carolina Pediatric Society, 1998), while not asking for a complete ban on the use of children in advertising, does call for the elimination of all eroticized or sexualized portrayals of children, including 'using preadolescent girls made up to mimic adults in sexualized poses, invoking adult sexual themes by dressing or making up a child, and sexualizing the nudity of a child or child-like model'.
} 
potential for harm in publishing a photograph if the artist in her is pleased with the composition and invested in the photograph as an artistic object. It may be useful, then, to seek the advice of the child's advocate about both modelling and dissemination. For dissemination decisions, this might entail showing the proofs to the advocate and discussing them together. Some questions that you might want to consider include the following. How likely is it that the child would find the photo embarrassing, given the social norms present in the community? Is the child able to understand all of the aspects of the photograph that might impact an adult's consent decision? How likely is it that other people will treat the child differently after viewing the photograph? Is this different treatment likely to have a negative or a positive impact on the child (or both)? If a negative impact is anticipated, how severe is it expected to be, and can these negative interactions be mitigated in some way (for example, by minimizing contact between the child and those individuals who are likely to react negatively to the photographs)?

\section{Application to other domains}

Many of the questions we have raised could also apply to other domains in which a parent's creative or intellectual work, or their financial well-being, depends in part on their children. Obviously, other visual arts such as painting or sculpting raise many of the same kinds of concerns that photography does. One difference is that in these media some protection of privacy is often maintained, especially when the mode of representation is relatively abstract. On the other hand, because the representation is limited only by the artist's imagination, violent or sexually explicit images could be created without requiring that those elements be part of the experience of the child model. For example, using current computer technology one can take an innocuous picture of a child (for example, a school portrait) and digitally modify it so as to create child pornography. Although no harm came to the child during the photographic session, one would want to consider the harm that would result from the dissemination of these pictures.

Questions of privacy also arise for novelists, playwrights, and poets who use the lives and experiences of their children as material to be incorporated into their work, and for individuals who include information about their children in their own autobiographies or memoirs. ${ }^{6}$ Should a writer ask permission before sharing details of other people's lives? What does one do in the case of people who are intimate (as parents and children are), when the threads of the lives intermingle, so that it is impossible for the writer to tell her story without also telling part of her child's? Questions about consent and conflicting interests are also present in situations where it is the child who is doing the work, while the parent serves as a manager or coach (for example, acting, commercial modelling, and sports such as tennis, gymnastics, and figure skating). How can such a conflict of interest be negotiated?

Questions about consent, privacy, and conflict of interest could also be raised in our own occupational and intellectual realm- - sychological research. ${ }^{7}$ In our field, it is common for scholars to draw upon their own experiences as they develop and refine the research

\footnotetext{
${ }^{6}$ There are some parallels between photographs and memoirs on the one hand, and paintings, sculptures, novels, and poems on the other. The former afford less privacy to those depicted, but for the latter art forms, the artist has more leeway to present imaginative material which may be frightening, offensive, or embarrassing.

${ }^{7}$ We thank Kathryn Becker for helpful discussions on this topic.
} 
questions they ask, and as they conduct and interpret empirical studies. Psychologists interested in child development are likely to use the children in their lives as research subjects, at least informally. Sometimes the use of one's own child or grandchild as a research subject is very formal and clear (for example, Piaget, 1951; Shatz, 1994). We may also be more likely to allow our children to participate in the studies and experiments of our colleagues.

Many of the issues and questions that we discussed in the context of an artistic enterprise also arise in the context of a psychological study. What is actually happening during the research process? Are there any actions or experiences that might, in and of themselves, cause harm? What about the 'experimental gaze'? Would repeatedly participating in experiments lead one to feel a kind of objectification, and would this have detrimental consequences? Finally, although the dissemination of personal information is not typical in research reports of psychological studies, it is sometimes the case (especially for qualitative research or case studies) that specific anecdotes or quotes are included as part of the report. The same questions about whether we should wait until the child is older before publishing anything attributed to her or him arise in this domain as in the artistic.

Videotaping is sometimes a part of psychological studies. In the ethics review process, this is given special scrutiny. Typically, researchers are required to designate a date at which they will erase or destroy the tapes. This is done in order to protect the privacy of the research participants. This requirement is seen as especially important with child participants, because they may be embarrassed even by seemingly innocuous tapes when they are older. An exception is made, however, for tapes used for educational or training purposes (for example, to train research assistants on a coding technique, or to illustrate a particular point in conference presentations). Researchers will often use their own children (or the children of colleagues) for these tapes. The parents give an informal blanket permission for the viewing of the tapes by anyone at any time, with the understanding that there is no designated destruction date. Researchers also sometimes allow their children to be involved in research in ways that are more risky than is generally considered safe for the general population. Why would researchers waive their child's right to full protection? The argument in both of these cases is that the researcher/parent, by virtue of his or her expertise, is in a better position to make an informed decision about the possibility of harm than is a parent from the general population. Parents who are artists could, of course, make a similar argument about their ability to judge the possibility of harm to their child of serving as a photographic model. The assumption that parents are the best judges of what is best for their children may, indeed, be valid, both for artists and psychologists. We would argue, however, that the potential conflict of interest between the roles of parent and researcher (or parent and photographer) implies that we should, at the least, carefully consider whether and when that assumption is true.

\section{Conclusion}

Our purpose in writing this article was to contribute to a dialogue that addresses both the rights of children to privacy and self-determination and the rights of artists to free creative expression. Much discussion of these issues has been polarized. We invite artists, politicians, parents, caregivers, and other interested parties to think in more complicated ways about these issues. 
We have not made specific legal recommendations, mostly because our discussion focused on ambiguous cases (for example, an artist taking non-erotic nude photographs of his or her children) in which it seems likely that no harm will befall the child. To invoke the law in these situations may be too repressive. Note, though, that because one of the functions of the legal system is to determine whether a plaintiff has been harmed, even ambiguous cases could be argued to fall within the purview of the legal system. Most likely, however, these more ambiguous situations will not receive attention beyond the private sphere. This lack of legal attention heightens rather than lessens the artist's responsibility to protect the child/model. We therefore encourage artists to think deeply about these issues and to engage in discussions with others both inside and outside the artistic community about what their personal boundaries will be.

We also encourage a continued dialogue on children's rights; these ideas do not yet come naturally to many of us, because they are so new. It is especially important to think about issues related to consent. In particular, when parents rather than children must give consent, how do we determine whose interests are being served?

More broadly, we are advocates of a continued discussion of privacy and ownership in art and journalism. Do people have the right of ownership of images of themselves, of their own stories, experiences, and realities? When are these rights relinquished and what is the process whereby this happens?

Discussion about children posing for photographs has mostly relied upon theoretical and philosophical arguments, as opposed to arguments grounded in empirical evidence. While all of these modes of discourse are valuable, we believe the discussion of the potential benefit or harm to children would be enriched by the introduction of more empirical data, and we encourage researchers to address this issue.

\section{References}

Browne A, Finkelhor D. 1986. Impact of child sexual abuse: a review of the research. Psychological Bulletin 99: 66-77.

Csikszentmihalyi M. 1990. Flow: The Psychology of Optimal Experience. Harper Perennial: New York.

Dhaliwal GK, Gauzas L, Antonowicz DH, Ross RR. 1996. Adult male survivors of childhood sexual abuse: prevalence, sexual abuse characteristics, and long-term effects. Clinical Psychology Review 16: 619-639.

Dix T. 1992. Parenting on behalf of the child: empathic goals in the regulation of responsive parenting. In Parental Belief Systems: The Psychological Consequences for Children (2nd edn), Sigel IE, McGillicuddy-DeLisi AV, Goodnow JJ (eds). Erlbaum: Hillsdale, NJ; 319-346.

Fredrickson BL, Roberts T. 1997. Objectification theory: toward understanding women's lived experiences and mental health risks. Psychology of Women Quarterly 21: 173-206.

Freyd JJ. 1994. Betrayal-trauma: traumatic amnesia as an adaptive response to childhood abuse. Ethics and Behavior 4: 307-329.

Freyd JJ. 1996. Betrayal Trauma: The Logic of Forgetting Childhood Abuse. Harvard University Press: Cambridge, MA.

Freyd JJ. 1997. Violations of power, adaptive blindness, and betrayal trauma theory. Feminism and Psychology 7: 22-32.

Freyd JJ. 1999. Blind to betrayal: new perspectives on memory for trauma. The Harvard Mental Health Letter 15(12): 4-6. 
Freyd JJ. 2002. Memory and dimensions of trauma: terror may be 'All-too-well remembered' and betrayal buried. In Critical Issues in Child Sexual Abuse: Historical, Legal, and Psychological Perspectives, Conte JR (ed.). Sage: Thousand Oaks, CA; 139-173.

Goddard CR, Stanley JR. 1994. Viewing the abusive parent and the abuse child as captor and hostage. Journal of Interpersonal Violence 9: 258-269.

Greenhouse L. 2002. 'Virtual' child pornography ban overturned. New York Times, 17 April, p. A1.

Hart SN. 1991. From property to person status: historical perspective on children's rights. American Psychologist 46: 53-59.

Mann S. 1988. At Twelve: Portraits of Young Women. Aperture: New York.

Mann S. 1998. Comments in response to the virtual roundtable. Politicizing Puberty: The Zoning of Child Sexuality in Art, Advertising and the American Household. Available: http://www.nerve.com/ Dispatches/voicebox/puberty/Mann_Answer3.asp [1 August 2002].

North Carolina Pediatric Society, Committee on Child Abuse and Neglect. 1998. Let Kids be Kids. Available: http://www.mindspring.com/ ncccan/ccan/index.html [1 August 2002].

Pardeck JT. 2002. Children's Rights: Policy and Practice. Haworth: New York.

Peterson DI. 2002. Child pornography on the internet: the effect of Section 230 of the Communications Decency Act of 1996 on tort recovery for victims against internet service providers. University of Hawaii Law Review 24: 763-795.

Piaget J. 1951. Play, Dreams and Imitation in Childhood. Norton: New York.

Putnam FW, Trickett PK. 1993. Child sexual abuse: a model of chronic trauma. In Children and Violence, Reiss D, Richters JE, Radke-Yarrow M, Scharff D (eds). Guilford: New York; 82-95.

Shatz M. 1994. A Toddler's Life: Becoming a Person. Oxford University Press: New York.

Shay J. 1994. Achilles in Vietnam: Combat Trauma and the Undoing of Character. Atheneum. New York.

Story MD. 1979. Factors associated with more positive body self-concepts in preschool children. Journal of Social Psychology 108: 49-56.

Sturges J. 1991. The Last Day of Summer. Aperture: New York.

Summit RC. 1983. The child sexual abuse accommodation syndrome. Child Abuse and Neglect 7: 177-193.

Svedin CG, Back K. 1996. Children Who Don't Speak Out: About Children Being Used in Child Pornography, Cracknell P (trans.). Scandbook: Falun, Sweden.

\section{Contributors' details}

Eileen L. Zurbriggen is an assistant professor in the psychology department at the University of California, Santa Cruz; her work on this article was supported in part by National Institute of Mental Health postdoctoral National Research Service Award F32MH12068.

Gale E. Pearce is a social psychology doctoral student at the University of Oregon.

Jennifer J. Freyd, Professor of Psychology at the University of Oregon, is the author of Betrayal Trauma: The Logic of Forgetting Childhood Abuse (1996, Harvard University Press) and the co-editor of Trauma \& Cognitive Science, (2001, Haworth Press). 